\title{
FDA Approval
}

National Cancer Institute

\section{Source}

National Cancer Institute. FDA Approval. NCI Thesaurus. Code C71735.

A written regulatory communication from FDA to an applicant, who submitted request to the agency to approve marketing or to license medical product, stating that the agency can approve the application or abbreviated application if specific additional information or material is submitted or specific conditions are met. An approvable letter does not constitute approval of any part of an application or abbreviated application and does not permit marketing of the drug that is the subject of the application or abbreviated application. The letter often lists minor deficiencies in the product documentation that have to be corrected, often involves labeling changes, and possibly requests sponsor commitment to do post-approval studies. 